Published in final edited form as:

Neuroimage. 2013 June ; 73: 113-120. doi:10.1016/j.neuroimage.2013.01.062.

\title{
Ultra high-resolution fMRI and electrophysiology of the rat primary somatosensory cortex 2 t
}

\author{
Yen-Yu lan Shih ${ }^{a, b, c, d,{ }^{*}, \text { You-Yin Chen }}{ }^{e}$, Hsin-Yi Laia,b, Yu-Chieh Jill Kao ${ }^{a, b}$, Bai-Chuang \\ Shyu $\mathrm{u}^{\mathrm{f}}$, and Timothy Q. Duong ${ }^{\mathrm{d}, \mathrm{g},{ }^{* *}}$ \\ aDepartment of Neurology, University of North Carolina, Chapel Hill, NC, USA \\ ${ }^{b}$ Biomedical Research Imaging Center, University of North Carolina, Chapel Hill, NC, USA \\ 'Department of Biomedical Engineering, University of North Carolina, Chapel Hill, NC, USA \\ ${ }^{d}$ Research Imaging Institute, University of Texas Health Science Center at San Antonio, San \\ Antonio, TX, USA \\ eDepartment of Biomedical Engineering, National Yang-Ming University, Taipei, Taiwan \\ IInstitute of Biomedical Science, Academia Sinica, Taipei, Taiwan \\ gDepartment of Ophthalmology, Radiology, and Physiology, University of Texas Health Science \\ Center at San Antonio, San Antonio, TX, USA
}

\begin{abstract}
High-resolution functional-magnetic-resonance-imaging (fMRI) has been used to study brain functions at increasingly finer scale, but whether fMRI can accurately reflect layer-specific neuronal activities is less well understood. The present study investigated layer-specific cerebralblood-volume (CBV) fMRI and electrophysiological responses in the rat cortex. CBV fMRI at $40 \times 40 \mu \mathrm{m}$ in-plane resolution was performed on an 11.7-T scanner. Electrophysiology used a 32channel electrode array that spanned the entire cortical depth. Graded electrical stimulation was used to study activations in different cortical layers, exploiting the notion that most of the sensoryspecific neurons are in layers II-V and most of the nociceptive-specific neurons are in layers VVI. CBV response was strongest in layer IV of all stimulus amplitudes. Current source density analysis showed strong sink currents at cortical layers IV and VI. Multi-unit activities mainly appeared at layers IV-VI and peaked at layer V. Although our measures showed scaled activation profiles during modulation of stimulus amplitude and failed to detect specific recruitment at layers $\mathrm{V}$ and VI during noxious electrical stimuli, there appears to be discordance between CBV fMRI and electrophysiological peak responses, suggesting neurovascular uncoupling at laminar resolution. The technique implemented in the present study offers a means to investigate intracortical neurovascular function in the normal and diseased animal models at laminar resolution.
\end{abstract}

\footnotetext{
Grant support: This work was supported in part by the American Heart Association (10POST4290091), Clinical Translational Science Awards (CTSA, parent grant UL1RR025767), and San Antonio Area Foundation to YYIS and the NIH/NINDS R01 NS45879 and VA MERIT to TQD.

(C) 2013 Published by Elsevier Inc.

*Correspondence to: Y.Y.I. Shih, Experimental Neuroimaging Laboratory, Departments of Neurology and Biomedical Research Imaging Center, 130 Mason Farm Road, CB\# 7513, University of North Carolina, Chapel Hill, NC 27599, USA. Fax: +1 919843 4456. shihy@unc.edu (Y.-Y.I. Shih). * Correspondence to: T.Q. Duong, Research Imaging Institute, University of Texas Health Science Center at San Antonio, 8403 Floyd Curl Drive, San Antonio, TX 78229, USA. Fax: +1 2105678152 . duongt@uthscsa.edu (T.Q. Duong).
} 


\section{Keywords}

fMRI; High-resolution; Cerebral blood volume; Local field potential; Current source density; Somatosensory cortex; Rat

\section{Introduction}

Recent technical improvements in magnetic resonance imaging (MRI) have helped to advance the spatial resolution of functional MRI (fMRI) to study brain activities in fine cortical structures, including resolving hemodynamic functions from individual cortical columns (Duong et al., 2001; Fukuda et al., 2006; Kim and Fukuda, 2008; Kim et al., 2000) and cortical layers (Harel et al., 2006; Jin and Kim, 2008; Logothetis et al., 2002; Lu et al., 2004; Shen et al., 2008; Siero et al., 2011; Smirnakis et al., 2007; Tian et al., 2010; Zhao et al., 2006), but how well those fMRI signals can represent regional neuronal activities remains debated. At a coarse spatial resolution, blood-oxygenation-level-dependent (BOLD) signal has been found to linearly correlate with evoked electrophysiological signals (Brinker et al., 1999; Disbrow et al., 2000; Goloshevsky et al., 2008; Huttunen et al., 2008; Masamoto et al., 2007; Ogawa et al., 2000; Van et al., 2006). Logothetis et al. (2001) demonstrated that local field potential (LFP) shows better correlation and provides a better estimate of the BOLD impulse response compared with multi-unit spike activity (MUA) by simultaneously recording BOLD and electrophysiology signals in the monkey visual cortex. It was later confirmed that the tissue oxygen tension is evident in the cat visual cortex when spike activity is absent and the LFP still exists (Viswanathan and Freeman, 2007). These data suggest that the BOLD hemodynamics correlate better with synaptic input (LFP) than output (spike). LFP is mainly generated from pyramidal cells whose dendrites extend throughout the cortex. An electric dipole with two charges of opposite polarity usually generated from the pyramidal cells and spans across the entire cortical depth. At high resolution, the power of LFP cannot be considered as a local measure of neuronal activity due to the lack of laminar resolution of the dipole (Buzsaki et al., 2012; Kajikawa and Schroeder, 2011). Current source density (CSD) analysis converts LFPs at different laminar locations into electrical current distribution, providing localization of electrophysiological sinks (inward membrane currents) and sources (outward membrane currents), where sinks correspond to dendritic excitatory postsynaptic potentials and sources correspond to passive efflux of charge from neuronal cell bodies (Freeman and Nicholson, 1975; Mitzdorf, 1987). High-resolution fMRI has been used to resolve responses in different cortical laminae. Most of the gradient-echo BOLD fMRI studies showed that the responses exhibited less spatial specificity to intra-cortical neuronal activities because the oxygenation changes were evident in large draining vessels on the cortical surface. BOLD signals have the shortest onset time in layers IV-V (Siero et al., 2011; Silva and Koretsky, 2002; Silva et al., 2007), but with only a few exceptions (Koopmans et al., 2010; Logothetis et al., 2002; Olman et al., 2012), the gradient-echo BOLD signals were generally highest in the superficial layer and the signals decreased monotonically with cortical depth in rats (Duong et al., 2000; Shen et al., 2008; Silva and Koretsky, 2002; Silva et al., 2000; Yu et al., 2012), cats (Harel et al., 2006; Jin and Kim, 2008; Zhao et al., 2004, 2006), monkeys (Smirnakis et al., 2007), and humans (Polimeni et al., 2010; Siero et al., 2011). In contrast, spin-echo fMRI (Duong et al., 2003; Lee et al., 1999; Zhao et al., 2006), similar to cerebral blood flow (CBF), cerebral blood volume (CBV), and oxygen metabolism fMRI (Harel et al., 2006; Jin and Kim, 2008; Lu et al., 2004; Shen et al., 2008) has more similar layer specificity to electrophysiology, showing activations predominantly in the cortical layers IV-V because this technique is less susceptible to large vessel contributions. 
Albeit there are many studies showing spatial correlations between functional hyperemia and synaptic activities, neurovascular coupling was found only at certain stimulus conditions (Nielsen and Lauritzen, 2001) and the flow-neuronal activity relationship was shown to be nonlinear after passing a certain threshold (Devor et al., 2003; Hewson-Stoate et al., 2005; Jones et al., 2004; Sheth et al., 2004), indicating that the hemodynamic response may not simply reflect the regional synaptic activities. The present study aimed to examine the relation between CBV fMRI signal and neural activity as a function of cortical depth at ultra-high spatial resolution. We hypothesized that CBV fMRI responses are not tightly coupled to electrophysiology measures (MUA and CSD) across different cortical layers at high spatial resolution. Iron-oxide CBV fMRI was utilized because it has improved functional contrast to noise ratio and laminar specificity. We also hypothesized that graded electrical stimulation can evoke preferential activations in the middle and deep cortical layers based on the fact that cortical neurons driven by non-noxious stimulation were mainly recorded from layers II-V, while most of the nociceptive specific neurons were found in layers V-VI (Lamour et al., 1983a).We implemented high-resolution CBV fMRI with a custom-made small surface coil at high field to achieve high signal-to-noise ratio and $40 \times 40$ $\mu \mathrm{m}$ in-plane resolution. LFP and MUA were recorded using a custom-designed 32-channel electrode array covering the entire cortical depth with high spatial resolution $(74 \mu \mathrm{m}$ interelectrode distance). These electrodes provided better sensitivity and accuracy because of closer proximity to sites of neural events.

\section{Materials and methods}

\section{Subjects}

A total of 16 adult male Sprague Dawley rats (weighing 250-300 g; Charles River Laboratories) were studied. All experimental procedures were approved by the Institutional of Animal Care and Utilization Committee, UT Health Science Center at San Antonio. Animals were housed in the vivarium (12:12-h light-dark cycle, controlled humidity and temperature) with free access to food and water.

\section{Animal preparation}

Rats were initially anesthetized with $3 \%$ isoflurane and orotracheally intubated for mechanical ventilation (Model 683, Harvard Apparatus, South Natick, MA). A PE-50 catheter was cannulated to the right femoral vein for subsequent drug administration. After the animal was secured in a MRI compatible rat stereotaxic headset, isoflurane was discontinued and a-chloralose ( $60 \mathrm{mg} / \mathrm{kg}$ first dose, followed by $30 \mathrm{mg} / \mathrm{kg} / \mathrm{h}$, i.v. infusion) was administered for anesthesia. The rat was then paralyzed with pancuronium bromide (3 $\mathrm{mg} / \mathrm{kg}$ first dose, followed by $1.5 \mathrm{mg} / \mathrm{kg} / \mathrm{h}$, i.v.). End-tidal $\mathrm{CO}_{2}$ was continuously monitored via a capnometer (Surgivet, Smith Medical, Waukesha, WI). Non-invasive end-tidal $\mathrm{CO}_{2}$ values were previously compared to invasive blood-gas samplings under identical experimental conditions (Shih et al., 2012b) and kept in normal ranges (3-3.3\%), corresponding to arterial $\mathrm{pCO}_{2}$ of $30-40 \mathrm{~mm} \mathrm{Hg}$. Rectal temperature was maintained at $37.0 \pm 0.5^{\circ} \mathrm{C}$ with warm-water circulating pad. Heart rate and blood oxygen saturation level were continuously monitored by a MouseOx system (STARR Life Science Corp., Oakmont, PA) and maintained within normal ranges. An established CBV fMRI technique was employed (Mandeville et al., 1998) by using $30 \mathrm{mg} / \mathrm{kg}$ monocrystalline iron oxide nanoparticles (MION) at 11.7 T to minimize the BOLD contribution (Shih et al., 2011, 2012c).

\section{Forepaw stimulation}

Electrical stimulation was achieved via a pair of needle electrodes inserted under the skin of the right forepaw (between digits 1 and 2 and digits 3 and 4). The electrodes were then fixed 
with surgical tape and the stimulation was confirmed by observing digit twitching. Graded electrical stimulation was applied using a stimulator (Model 2100, A-M Systems, Carlsborg, Washington, USA) with a constant current at 1,2,6, and $10 \mathrm{~mA}$ with a pulse-width of 0.3 $\mathrm{ms}$ at $3 \mathrm{~Hz}$. Each stimulus amplitude was presented at least once to each animal in a random order. Stimulation current above $2 \mathrm{~mA}$ is considered to induce nociception (Lowe et al., 2007; Shih et al., 2009, 2011, 2012a). A block-design stimulus paradigm was OFF-ON$\mathrm{OFF}-\mathrm{ON}-\mathrm{OFF}$ for $\mathrm{fMRI}$ and $\mathrm{OFF}-\mathrm{ON}-\mathrm{OFF}$ for electrophysiology, where $\mathrm{OFF}=100 \mathrm{~s}$ and $\mathrm{ON}=50 \mathrm{~s}$.

\section{fMRI data acquisition}

MRI was performed in a group of six rats. MR images were acquired using an $11.7 \mathrm{~T} / 16 \mathrm{~cm}$ magnet and a $74 \mathrm{G} / \mathrm{cm}$ B-GA9S gradient insert (Bruker, Billerica, MA). A custom-made small circular surface coil (ID $\sim 0.7 \mathrm{~cm}$ ) was placed above the contralateral primary somatosensory cortex of the forelimb (S1FL). Magnetic field homogeneity was optimized using standard FASTMAP shimming with first order shims on an isotropic voxel of $7 \times 7 \times 7$ $\mathrm{mm}$ encompassing the imaging slices. A $\mathrm{T}_{2}$-weighted pilot image was taken in the midsagittal plane to localize the anatomical position by identifying the anterior commissure (bregma $-0.8 \mathrm{~mm}$ ). Imaging slice was oriented perpendicular to the cortical surface for better cortical layer alignment (Fig. 1). CBV fMRI was acquired with FLASH sequence using spectral width $=14.8 \mathrm{kHz}, \mathrm{TR} / \mathrm{TE}=26 / 10 \mathrm{~ms}, \mathrm{FOV}=0.768 \times 0.768 \mathrm{~cm}$, slice thickness $=2 \mathrm{~mm}$, matrix $=192 \times 192$, yielding in-plane resolution $=40 \times 40 \mu \mathrm{m}$ and temporal resolution $=5 \mathrm{~s}$. The flip angle of the FLASH sequence was adjusted to maximize the signal in the S1FL, which was the Ernst angle $\left(\sim 10^{\circ}\right)$. High in-plane resolution is needed to unambiguously resolve layer-specific responses because the thickness of cortical layer IV in the $\mathrm{S} 1$ area is only about $250 \mu \mathrm{m}$ (Sun et al., 2006).

\section{Electrophysiology recording}

Electrophysiology was performed in a separate group of five rats. A stereotaxic frame (Model 900, David Kopf Instruments, Tujunga, CA, USA) was used to position the head. The animal physiological conditions were kept the same as the MRI experiment, except that craniotomies were performed over the S1FL area contralateral to the stimulated forepaw to implant the recording electrode. A stainless steel screw was placed $2 \mathrm{~mm}$ caudal to lambda as a reference electrode. After the dura was removed, a custom designed polyimide-based 32-channel microelectrode array (Chen et al., 2009) was implanted at the S1FL (coordinates from Bregma: AP, $+0.5 \mathrm{~mm}$; ML, $-4 \mathrm{~mm}$; and $\mathrm{VD},-2 . \mathrm{mm}$; approached with a coronal angle of $22.5^{\circ}$ ). The spacing between two adjacent channels was $74 \mu \mathrm{m}$. The diameter of the electrode was $16 \mu \mathrm{m}$. Data were acquired using a Cerebus multi-channel data acquisition system (Blackrock Microsystems, Salt Lake City, Utah, USA). The data were amplified and filtered into: LFP (0.3-500 Hz and sampled at $1 \mathrm{kHz}$ ) and MUA (150 to $5000 \mathrm{~Hz}$ and sampled at $20 \mathrm{kHz}$ ). At the end of the experiment, a $30 \mu \mathrm{A}$ direct-current was delivered to the deepest contact lead for $10 \mathrm{~s}$ to label the recording site. The rats were then given an overdose of anesthetic and perfused with a mixture of $150 \mathrm{ml}$ ice-cold PBS solution and 500 $\mathrm{ml} 4 \%$ paraformaldehyde at the flow rate of $50 \mathrm{ml} / \mathrm{min}$. The brains were carefully removed from the skulls and kept in a mixture of $4 \%$ paraformaldehyde and $30 \%$ sucrose at $4{ }^{\circ} \mathrm{C}$ for two days. Afterwards, each brain was sliced into $50 \mu \mathrm{m}$ coronal sections with a freezing microtome (CM 1800, Leica, Germany). Nissl staining of brain tissue sections with $0.1 \%$ cresyl violet was used to confirm the recording locations.

\section{Data analysis}

Image analysis was performed using a custom-written program in Matlab (Math-Works, Natick, MA), STIMULATE (University of Minnesota), and Statistical Parametric Mapping (SPM). Time series MRI data were co-registered to align slight image drift overtime using 
the spatial realignment function in SPM5 (Duong and Muir, 2009; Muir and Duong, 2011). Spatial translation and rotation were applied automatically to co-register images showing difference from the mean image averaged across the entire time-series using mutual information. The stimulus-evoked $\Delta \mathrm{R}_{2} *$ value, which varies linearly with the stimulusevoked CBV fraction, was calculated as follows (Mandeville et al., 1998) after MION injection: $\Delta \mathrm{R}_{2}{ }^{*}=\frac{1}{\mathrm{TE}} \ln \left(\mathrm{S}_{\mathrm{ctrl}} / \mathrm{S}_{\mathrm{stim}}\right)$, where $\mathrm{S}_{\mathrm{ctrl}}$ and $\mathrm{S}_{\text {stim }}$ are the MR signal intensities before and during stimulation, respectively. The stimulus-evoked percent-CBV change was further computed by dividing the basal CBV: $\% \mathrm{CBV}=\frac{\ln \left(\mathrm{S}_{\mathrm{ctrl}} / \mathrm{S}_{\mathrm{stim}}\right)}{\ln \left(\mathrm{S}_{\text {pre-MION }} / \mathrm{S}_{\mathrm{ctrl}}\right)}$, where $\mathrm{S}_{\text {pre-MION }}$ is the MR signal intensity before MION injection. Intensity profiles across the entire cortical depth $(2 \mathrm{~mm})$ were obtained from flattened images by projecting lines perpendicular to the cortical surface on a T2-weighted image coregistered to the time-series data. Profiles were then averaged along the length of the S1FL $(\sim 1.3 \mathrm{~mm})$ and plotted as a function of time. The signals along the cortical depth were assigned to five pre-defined cortical layers according to Nissl staining, where the percent-thickness of layers I, II-III, IV, V, and VI were 12\%, 20\%, $14 \%, 18 \%$, and $36 \%$ of the total cortical depth, respectively (Sun et al., 2006). Layerspecific stimulus-evoked percent CBV changes to different stimulus amplitudes were tabulated.

Electrophysiology data were analyzed by using custom-written codes in MATLAB. The $50 \mathrm{~s}$ LFP and MUA data during stimulation were split into 150 trials of 333 ms post-stimulus periods based on the stimulus time stamps $(3 \mathrm{~Hz})$. Averaged LFPs and MUAs were obtained by averaging over 150 trials. $\sum$ MUAs were then calculated as an integration of the area under the response curve during the $100 \mathrm{~ms}$ post-stimulus period. Current source-density (CSD) analysis (Freeman and Nicholson, 1975; Mitzdorf, 1987) processed averaged LFPs using a numerical approximation of the second finite differences as described previously (Wojcik and Leski, 2010). The relationship between LFP and CSD is described by a Poisson equation as follows (Freeman and Nicholson, 1975):

$$
\nabla \cdot J=-I_{m}=-\sigma \nabla^{2} \phi
$$

where $\sigma$ is the conductivity of the conducting medium and $\psi$ is the FP. The CSD units should be multiplied by the unit of conductivity. However, if the recording area is small, the tissue conductivities along all of the axes can be assumed to be homogeneous (McAllister and Wells, 1981). The equation can be simplified as follows:

$$
\nabla \cdot J=-I_{m}=-\sigma \nabla^{2} \phi
$$

And the approximation of trans-membrane current is

$$
I_{m}=-\left(\frac{1}{k h^{2}}\right) \sum_{m=-n}^{n} a_{m} \phi(x+m h)
$$

where $\phi$ is the extracellular field potential, $h$ is the distance between adjacent recording sites (74 $\mu \mathrm{m}$ ), and $x$ is the coordinate perpendicular to the cortical layer. The D2-filter was performed for spatial smoothing and the parameters $n, k$, and $a_{m}$ are constants as follows: $n$ $=2, k=4, a_{0}=-2, a_{ \pm 1}=0$ and $a_{ \pm 2}=1$ (Freeman and Nicholson,1975; Sun et al., 2006; Tenke et al., 1993). The brain tissue conductivity of $0.3 \mathrm{~S} / \mathrm{m}$ was used (Bédard and Destexhe, 2011; Goldenholz et al., 2009) and was assumed isotropic and homogeneous in 
the cortex (Chapman et al., 1998; Csicsvari et al., 2003). To compare with the CBV fMRI (reflecting overall metabolism-related hyperemia after stimulus) and IMUA, the peak amplitude of the first sink component after the stimulus onset was calculated.

Data were then averaged across subjects to provide group-averaged laminar profiles of evoked sink distribution and MUAs in the S1FL. Statistical analysis was performed by SPSS software (IBM, Armonk, NY, USA). Repeated-measures ANOVA with LSD post-hoc test was used. Homogeneity of the variances was assessed by Levene's test. The significance level was set at $P<0.05$. All data are presented as mean \pm SEM.

\section{Results}

Representative high-resolution CBV fMRI of the rat S1FL ( $40 \times 40 \mu \mathrm{m}$ in-plane resolution) is shown in Fig. 2A. A thick slice was used to increase the signal-to-noise ratio and minimize individual vessel contribution to the laminar CBV profiles. Nevertheless, column-like activations were still observed in the cortex which may originate from penetrating vessels perpendicular to the cortical surface. The cortex was linearized to facilitate layer analyses (Fig. 2B). Fig. 3A shows CBV profile time courses of 1, 2, 6, and $10 \mathrm{mAstimulation}(\mathrm{n}=6)$. No apparent spatial shift in the mediolateral direction was observed at different stimulus intensities; therefore data were averaged along the length of the cortex $(\sim 1.3 \mathrm{~mm})$ within the ROI (Fig. 2B) and plotted over time. The percent CBV changes varied with the cortical depth. The greatest signal changes occurred in cortical layer IV and decreased continuously toward both the cortical surface and corpus callosum. The basal CBV fraction at different cortical layers is shown in Fig. 3B. Cortical layer IV shows the higher CBV fraction compared with layers I and VI $(P<0.05)$. Percent CBV changes to graded forepaw electrical stimulation exhibited similar distribution as the basal CBV fraction (Fig. 3C), where a significantly stronger CBV response was observed at cortical layer IV compared with layers I and VI at all stimulus amplitudes $(P<0.05)$.

Fig. 4A shows LFP traces from a representative subject and Fig. 4B shows corresponding CSD traces calculated from the LFP data. The amplitudes of the first CSD sink peak were quantitatively expressed as a bar graph shown in Fig. 6A. Cortical layers IV and VI showed the greatest sink currents among all stimulus conditions. Fig. 5 shows MUA traces from a representative subject response to graded forepaw electrical stimulation. $\sum$ MUAs were stronger in cortical layer $\mathrm{V}$ compared to all other layers at 6 and $10 \mathrm{~mA}$ stimuli $(P<0.05$; Fig. 6B). Higher stimulus amplitude evoked greater MUA responses compared to $1 \mathrm{~mA}$ at all cortical layers $(P<0.05)$. Fig. $6 \mathrm{C}$ shows 32 equally spaced contacts of the electrode array that spanned the cortex for electrophysiological recording. At the end of the experiment, a small lesion was induced by passing $30 \mu \mathrm{A}$ anodal current to the last contact lead for $10 \mathrm{~s}$ to confirm the recording site by Nissl staining.

\section{Discussion}

The present study demonstrated high-resolution CBV fMRI and electrophysiological responses to graded forepaw electrical stimulation in the rat S1FL. The major findings were: (i) Column-like activations were observed using CBV fMRI at $40 \times 40 \mu \mathrm{m}$ in-plane resolution. Those column-like activations may result from vasodilation of small vessels located nearby the cortical microcolumns. (ii) CBV response was strongest in layer IV of all stimulus amplitudes. The activation profiles across cortical layers were similar among different stimulus amplitudes. (iii) CSD sink components that peaked at layers IV and VI were significantly stronger than other layers among all stimulus amplitudes. (iv) MUA mainly appeared in layers IV-VI and peaked at layer V during noxious stimuli. There appears to be discordance between CBV fMRI and electrophysiological peak responses, 
suggesting neurovascular uncoupling at laminar resolution. These data supported our hypothesis that fMRI does not accurately reflect electrophysiology measures at high spatial resolution.

\section{Laminar-specific neuronal activity}

Unmyelinated $\mathrm{C}$ primary afferent fibers have been found to carry nociceptive signals in rats (Lynn and Carpenter, 1982), monkeys (Croze et al., 1976), and humans (Torebjork, 1974; Van Hees and Gybels, 1972). Nociceptive neurons in the ventroposterior thalamic nuclei respond to electrical stimulation of cutaneous C-fibers (Guilbaud et al., 1980) and project to the S1 (Schouenborg et al., 1986). A $\delta$-fibers also respond to intense mechanical stimuli and nociception (Julius and Basbaum, 2001). In contrast, myelinated A $\beta$ primary afferent fibers primarily detect innocuous stimuli and consequently do not contribute to pain (Djouhri et al., 1998). Previous fMRI and electrophysiology studies showed that the responses of $A \beta-, A \delta-$, and $\mathrm{C}$-fibers reached their maximum amplitude and saturated when the nerve-stimulating currents were 10,15, and 20 times higher than the minimal current to evoke action potential, demonstrating that the graded electrical stimulation has potential to differentiate brain areas associated with nociception (Chang and Shyu, 2001). The rat cortex exhibits high laminar specificity to different stimulations. Cortical neurons driven by non-noxious cutaneous stimulation were mainly recorded from layers II-V (98\%), whereas most of the nociceptive specific neurons were found in layers V-VI (92\%) (Lamour et al., 1983a). A previous study using a combination of latency measurements, anodal block of A fiber conduction, and graded stimulation showed that the strong field potentials in layers V and VI were primarily evoked by nociceptive $C$ fiber input (Kalliomaki et al., 1993). By electrically stimulating the median nerve, Jellema et al. (2004) found that specific thalamic afferents first depolarized layer III and layer V pyramidal cells. After that, superficial pyramidal cells were depolarized via supragranular intracortical projections, and followed by the generation of spikes in layer $\mathrm{V}$ pyramidal cells, which enhanced supragranular pyramidal cell activation. Sun et al. further showed that noxious electrical stimulation of the rat hindpaw primarily evoked sink currents at layer IV and spread transynaptically upward to layers II-III. In addition, laser stimuli evoked a delayed sink current occurred at the boundary of layers V and VI and swept downward to deep layer VI (Sun et al., 2006). In short, the major excitatory intracortical circuits include: (i) the feed-forward circuit starting from layer IV to layer II/III, and then to layers V and VI. (ii) The feed-back circuit starting from layers V and VI to layers III and IV, and from layer III to layer IV (Bannister, 2005; Lubke and Feldmeyer, 2007; Schubert et al., 2007). Although CSD represents synaptic distribution in cortical layers, it reveals a static wiring organization instead of dynamic neuronal responses evoked by graded stimuli (Einevoll et al., 2007). Therefore, increasing the stimulus intensity would result in scaling of the amplitude of the same laminar profile as shown in our data.

MUA describes the aggregates of extracellular spikes and may be more suitable to address laminar responses to stimulus (Einevoll et al., 2007; Krupa et al., 2004; Sakata and Harris, 2009). According to the laminar architecture of the cortex, most of the cortical neurons are located in layers IV and VI (Helmstaedter et al., 2007; Meyer et al., 2010). Dense thalamocortical projections were also found in these layers (Bernardo and Woolsey, 1987; Herkenham, 1980; Keller et al., 1985; White, 1979). Although the number of neurons in layer V is less than layer IV or VI, the primary output action potentials were emitted by the thick-tufted cells in layer Vb (de Kock et al., 2007; Feldmeyer, 2012; Helmstaedter et al., 2007). High MUAs in layers IV-VI in our data were in good agreement with others reported previously (Meyer et al., 2010) and substantiates the cortical laminar cytoarchitecture. Our original hypothesis was that graded electrical stimulation at the rat forepaw was able to modulate laminar activation profile of MUA. However, our data failed to detect specific recruitment at layers V and VI during noxious electrical stimuli. Instead, a scaled activation 
profile was observed during graded electrical stimuli. This indicates that electrical stimulus at the forepaw is non-selective and the response in the cortical laminae may be contaminated by a variety of peripheral input, which eliminates the modality specificity across layers. Another potential explanation is that the amount of nociceptive neurons is relatively small in population. It has been shown that $29 \%$ of the neurons in the somatosensory cortex are sensory-related and only $8 \%$ are nociceptive-specific out of 694 neurons recorded in 26 rats (Lamour et al., 1983b). An alternative and more specific noxious stimulation, such as using $\mathrm{CO}_{2}$ laser to selectively evoke nociception without affecting other sensory modalities, or using optogenetics to activate a specific group of neurons in the defined cortical layers may be more suitable to study intracortical neurovascular coupling in the future.

\section{Laminar-specific CBV fMRI response}

High in-plane resolution is needed to resolve layer-specific responses because the thickness of cortical layer IV in the S1 area is only about $250 \mu \mathrm{m}$ (Sun et al., 2006). The hemodynamic responses have been shown to better reflect the input of the neural population rather than its output (Jones et al., 2004; Logothetis et al., 2001; Viswanathan and Freeman, 2007). Our CBV fMRI response only peaked at layer IV across all stimulus amplitudes and better correlated to the major synaptic input revealed by CSD. The sink currents in cortical layer VI and MUA peaked at layer V were not reflected by CBV fMRI. This may be due to the distribution of vascular network and the control of microcirculation in the cortex. In general, neurons inside the cortical layer IV have better somatotopic representation (Woolsey et al., 1996). High vascularity in layer IV (Fonta and Imbert, 2002; Lauwers et al., 2008; Patel, 1983; Smirnakis et al., 2007; Zheng et al., 1991) may be to accommodate greater metabolic needs compared with other layers (Kennedy et al., 1976; Kossut et al., 1988). The activation-induced CBV change was highly correlated with the basal CBV. In the rat cortex, the highest vessel density was found in layer IV. The vessel density in layer VI was only $10 \%$ that of layer IV and the vessels also decreased in size along the depth and diminished in layer V or VI (Patel, 1983). A lower basal CBV indicated less contrast enhancement and hence less sensitivity. It is likely that those sparse arterial terminals in layer VI respond minimally to adjacent neuronal activity or generate very weak CBV changes and thus resulting in poor spatial specificity of the CBV responses to the strong sink currents in layer VI. fMRI activation at high resolution has been suggested to spatially relate to functional vascular unit (Duong et al., 2001; Duvernoy et al., 1981; Harel et al., 2010; Kim et al., 2000). The microvascular structure in the rat cortex is highly organized but is not completely isolated. In cortical layer IV, dense vascular connections have been found between the cortical columns by micro-injecting dye into the arteriole (Woolsey et al., 1996). These microvessels in layer IV possess finer tuning of flow changes and can nourish the neighboring columns (Woolsey et al., 1996), which may lead to functional hyperemia occurring predominantly in layer IV during stimulation.

\section{Potential limitations}

Potential drawbacks of the present study were: (i) a relatively thick slice was used to increase the signal-to-noise ratio and minimize potential contribution from large penetrating vessels to the laminar CBV profiles. Therefore, the CBV fMRI signals may be susceptible to partial volume effect. The S1FL has reasonably uniform layer thickness and similar distribution of neurons/vasculature within each layer. We adjusted our slice angle to make it perpendicular to the cortical surface to reduce the error in layer assignment (Fig. 1). (ii) Electrophysiology was not performed simultaneously with fMRI and the recording volume was different. Future studies will focus on developing MR-compatible multichannel electrode arrays for simultaneous recording to eliminate the physiological variations in different subjects. (iii) Short TR may induce in-flow effect, which could reduce the negative MION fMRI signal change and result in incorrect estimate of CBV changes. Small flip angle 
$\left(\sim 10^{\circ}\right)$ was used in this study which minimized in-flow effects. Similar study that used long TR in MION fMRI showed that the layer-specific CBV response patterns were similar (Shen et al., 2008), suggesting that inflow effect with our TR was likely small. A high dose of MION used in this study also minimized the in-flow effect because the intra-vascular blood $\mathrm{T} 2 *$ value is dramatically shortened and thus invisible (Lu et al., 2004). (iv) In our CSD analysis, the extracellular medium is presumed to be uniform and resistive (Mitzdorf, 1985; Pettersen et al., 2006). The mismatch between CBV and CSD profiles could potentially be due to the negligible estimation of the surrounding extracellular medium in the CSD analysis since the ionic flow and polarization effect may alter the expression of current source (Bédard and Destexhe, 2011). (v) The borders of the layers were not individually identified and percent depth ratio was used for layer assignment. This may affect the quantitation of the layer responses.

\section{Conclusions}

The present study developed ultra-high-resolution fMRI and electrophysiology techniques to study neurovascular responses in the rat somatosensory cortex. The spatial resolution was $40 \times 40 \mu \mathrm{m}$ in-plane for CBV fMRI. The spacing between two adjacent recording sites for electrophysiology was $74 \mu \mathrm{m}$. CBV fMRI and electrophysiological data show different functional activation profiles across the cortical depth, peaking at different locations. These findings indicate that hemodynamic response may not exclusively reflect local neuronal activity, and may depend on the distribution and the reactivity of regional microvasculature. This technique offers a means to investigate intracortical neurovascular function in the normal and diseased animal models.

\section{References}

Bannister AP. Inter- and intra-laminar connections of pyramidal cells in the neocortex. Neurosci. Res. 2005; 53:95-103. [PubMed: 16054257]

Bédard C, Destexhe A. Generalized theory for current-source-density analysis in brain tissue. Phys. Rev. E. 2011; 84:041909.

Bernardo KL, Woolsey TA. Axonal trajectories between mouse somatosensory thalamus and cortex. J. Comp. Neurol. 1987; 258:542-564. [PubMed: 3584549]

Brinker G, Bock C, Busch E, Krep H, Hossmann KA, Hoehn-Berlage M. Simultaneous recording of evoked potentials and T2*-weighted MR images during somatosensory stimulation of rat. Magn. Reson. Med. 1999; 41:469-473. [PubMed: 10204868]

Buzsaki G, Anastassiou CA, Koch C. The origin of extracellular fields and currents-EEG, ECoG, LFP and spikes. Nat. Rev. Neurosci. 2012; 13:407-420. [PubMed: 22595786]

Chang C, Shyu BC. A fMRI study of brain activations during non-noxious and noxious electrical stimulation of the sciatic nerve of rats. Brain Res. 2001; 897:71-81. [PubMed: 11282360]

Chapman CA, Trepel C, Ivanco TL, Froc DJ, Wilson K, Racine RJ. Changes in field potentials and membrane currents in rat sensorimotor cortex following repeated tetanization of the corpus callosum in vivo. Cereb. Cortex. 1998; 8:730-742. [PubMed: 9863700]

Chen YY, Lai HY, Lin SH, Cho CW, Chao WH, Liao CH, Tsang S, Chen YF, Lin SY. Design and fabrication of a polyimide-based microelectrode array: application in neural recording and repeatable electrolytic lesion in rat brain. J. Neurosci. Methods. 2009; 182:6-16. [PubMed: 19467262]

Croze S, Duclaux R, Kenshalo DR. The thermal sensitivity of the polymodal nociceptors in the monkey. J. Physiol. 1976; 263:539-562. [PubMed: 1018278]

Csicsvari J, Henze DA, Jamieson B, Harris KD, Sirota A, Barthó P, Wise KD, Buzsáki G. Massively parallel recording of unit and local field potentials with silicon-based electrodes. J. Neurophysiol. 2003; 90:1314-1323. [PubMed: 12904510] 
de Kock CP, Bruno RM, Spors H, Sakmann B. Layer- and cell-type-specific suprathreshold stimulus representation in rat primary somatosensory cortex. J. Physiol. 2007; 581:139-154. [PubMed: 17317752]

Devor A, Dunn AK, Andermann ML, Ulbert I, Boas DA, Dale AM. Coupling of total hemoglobin concentration, oxygenation, and neural activity in rat somatosensory cortex. Neuron. 2003; 39:353-359. [PubMed: 12873390]

Disbrow EA, Slutsky DA, Roberts TP, Krubitzer LA. Functional MRI at 1.5 tesla: a comparison of the blood oxygenation level-dependent signal and electrophysiology. Proc. Natl. Acad. Sci. U. S. A. 2000; 97:9718-9723. [PubMed: 10931954]

Djouhri L, Bleazard L, Lawson SN. Association of somatic action potential shape with sensory receptive properties in guinea-pig dorsal root ganglion neurones. J. Physiol. 1998; 513(Pt. 3):857872. [PubMed: 9824723]

Duong TQ, Muir ER. Magnetic resonance imaging of the retina. Jpn.J. Ophthalmol. 2009; 53:352-367. [PubMed: 19763752]

Duong TQ, Silva AC, Lee SP, Kim SG. Functional MRI of calcium-dependent synaptic activity: cross correlation with CBF and BOLD measurements. Magn. Reson. Med. 2000; 43:383-392. [PubMed: 10725881]

Duong TQ, Kim DS, Ugurbil K, Kim SG. Localized cerebral blood flow response at submillimeter columnar resolution. Proc. Natl. Acad. Sci. U. S. A. 2001; 98:10904-10909. [PubMed: 11526212]

Duong TQ, Yacoub E, Adriany G, Hu X, Ugurbil K, Kim SG. Microvascular BOLD contribution at 4 and $7 \mathrm{~T}$ in the human brain: gradient-echo and spin-echo fMRI with suppression of blood effects. Magn. Reson. Med. 2003; 49:1019-1027. [PubMed: 12768579]

Duvernoy HM, Delon S, Vannson JL. Cortical blood vessels of the human brain. Brain Res. Bull. 1981; 7:519-579. [PubMed: 7317796]

Einevoll GT, Pettersen KH, Devor A, Ulbert I, Halgren E, Dale AM. Laminar population analysis: estimating firing rates and evoked synaptic activity from multielectrode recordings in rat barrel cortex. J. Neurophysiol. 2007; 97:2174-2190. [PubMed: 17182911]

Feldmeyer D. Excitatory neuronal connectivity in the barrel cortex. Front. Neuroanat. 2012; 6:24. [PubMed: 22798946]

Fonta C, Imbert M. Vascularization in the primate visual cortex during development. Cereb. Cortex. 2002; 12:199-211. [PubMed: 11739267]

Freeman JA, Nicholson C. Experimental optimization of current source-density technique for anuran cerebellum. J. Neurophysiol. 1975; 38:369-382. [PubMed: 165272]

Fukuda M, Moon CH, Wang P, Kim SG. Mapping iso-orientation columns by contrast agent-enhanced functional magnetic resonance imaging: reproducibility, specificity, and evaluation by optical imaging of intrinsic signal. J. Neurosci. 2006; 26:11821-11832. [PubMed: 17108155]

Goldenholz DM, Ahlfors SP, Hämäläinen MS, Sharon D, Ishitobi M, Vaina LM, Stufflebeam SM. Mapping the signal-to-noise-ratios of cortical sources in magne-toencephalography and electroencephalography. Hum. Brain Mapp. 2009; 30:1077-1086. [PubMed: 18465745]

Goloshevsky AG, Silva AC, Dodd SJ, Koretsky AP. BOLD fMRI and somatosensory evoked potentials are well correlated over a broad range of frequency content of somatosensory stimulation of the rat forepaw. Brain Res. 2008; 1195:67-76. [PubMed: 18206862]

Guilbaud G, Peschanski M, Gautron M, Binder D. Neurones responding to noxious stimulation in VB complex and caudal adjacent regions in the thalamus of the rat. Pain. 1980; 8:303-318. [PubMed: 7402691]

Harel N, Lin J, Moeller S, Ugurbil K, Yacoub E. Combined imaging-histological study of cortical laminar specificity of fMRI signals. NeuroImage. 2006; 29:879-887. [PubMed: 16194614]

Harel N, Bolan PJ, Turner R, Ugurbil K, Yacoub E. Recent advances in high-resolution MR application and its implications for neurovascular coupling research. Front. Neuroenerg. 2010; 2:130.

Helmstaedter M, de Kock CP, Feldmeyer D, Bruno RM, Sakmann B. Reconstruction of an average cortical column in silico. Brain Res. Rev. 2007; 55:193-203. [PubMed: 17822776]

Herkenham M. Laminar organization of thalamic projections to the rat neocortex. Science. 1980; 207:532-535. [PubMed: 7352263] 
Hewson-Stoate N, Jones M, Martindale J, Berwick J, Mayhew J. Further nonlinearities in neurovascular coupling in rodent barrel cortex. NeuroImage. 2005; 24:565-574. [PubMed: 15627599]

Huttunen JK, Grohn O, Penttonen M. Coupling between simultaneously recorded BOLD response and neuronal activity in the rat somatosensory cortex. NeuroImage. 2008; 39:775-785. [PubMed: 17964186]

Jellema T, Brunia CH, Wadman WJ. Sequential activation of microcircuits underlying somatosensoryevoked potentials in rat neocortex. Neuroscience. 2004; 129:283-295. [PubMed: 15501587]

Jin T, Kim SG. Cortical layer-dependent dynamic blood oxygenation, cerebral blood flow and cerebral blood volume responses during visual stimulation. NeuroImage. 2008; 43:1-9. [PubMed: 18655837]

Jones M, Hewson-Stoate N, Martindale J, Redgrave P, Mayhew J. Nonlinear coupling of neural activity and CBF in rodent barrel cortex. NeuroImage. 2004; 22:956-965. [PubMed: 15193627]

Julius D, Basbaum AI. Molecular mechanisms of nociception. Nature. 2001; 413:203-210. [PubMed: 11557989]

Kalliomaki J, Weng HR, Nilsson HJ, Schouenborg J. Nociceptive C fibre input to the primary somatosensory cortex (SI). A field potential study in the rat. Brain Res. 1993; 622:262-270. [PubMed: 8242365]

Kajikawa Y, Schroeder CE. How local is the local field potential? Neuron. 2011; 72:847-858. [PubMed: 22153379]

Keller A, White EL, Cipolloni PB. The identification of thalamocortical axon terminals in barrels of mouse Sml cortex using immunohistochemistry of anterogradely transported lectin (Phaseolus vulgaris-leucoagglutinin). Brain Res. 1985; 343:159-165. [PubMed: 4041849]

Kennedy C, Des Rosiers MH, Sakurada O, Shinohara M, Reivich M, Jehle JW, Sokoloff L. Metabolic mapping of the primary visual system of the monkey by means of the autoradiographic [14C]deoxyglucose technique. Proc. Natl. Acad. Sci. U. S. A. 1976; 73:4230-4234. [PubMed: 825861]

Kim SG, Fukuda M. Lessons from fMRI about mapping cortical columns. Neuroscientist. 2008; 14:287-299. [PubMed: 17989170]

Kim DS, Duong TQ, Kim SG. High-resolution mapping of iso-orientation columns by fMRI. Nat. Neurosci. 2000; 3:164-169. [PubMed: 10649572]

Koopmans PJ, Barth M, Norris DG. Layer-specific BOLD activation in human V1. Hum. Brain Mapp. 2010; 31:1297-1304. [PubMed: 20082333]

Kossut M, Hand PJ, Greenberg J, Hand CL. Single vibrissal cortical column in SI cortex of rat and its alterations in neonatal and adult vibrissa-deafferented animals: a quantitative 2DG study. J. Neurophysiol. 1988; 60:829-852. [PubMed: 3171652]

Krupa DJ, Wiest MC, Shuler MG, Laubach M, Nicolelis MA. Layer-specific somatosensory cortical activation during active tactile discrimination. Science. 2004; 304:1989-1992. [PubMed: 15218154]

Lamour Y, Guilbaud G, Willer JC. Rat somatosensory (SmI) cortex: II. Laminar and columnar organization of noxious and non-noxious inputs. Exp. Brain Res. 1983a; 49:46-54. [PubMed: 6861936]

Lamour Y, Willer JC, Guilbaud G. Rat somatosensory (SmI) cortex: I. Characteristics of neuronal responses to noxious stimulation and comparison with responses to non-noxious stimulation. Exp. Brain Res. 1983b; 49:35-45. [PubMed: 6861935]

Lauwers F, Cassot F, Lauwers-Cances V, Puwanarajah P, Duvernoy H. Morphometry of the human cerebral cortex microcirculation: general characteristics and space-related profiles. NeuroImage. 2008; 39:936-948. [PubMed: 17997329]

Lee SP, Silva AC, Ugurbil K, Kim SG. Diffusion-weighted spin-echo fMRI at 9.4 T: microvascular/ tissue contribution to BOLD signal changes. Magn. Reson. Med. 1999; 42:919-928. [PubMed: 10542351]

Logothetis NK, Pauls J, Augath M, Trinath T, Oeltermann A. Neurophysiological investigation of the basis of the fMRI signal. Nature. 2001; 412:150-157. [PubMed: 11449264] 
Logothetis N, Merkle H, Augath M, Trinath T, Ugurbil K. Ultra high-resolution fMRI in monkeys with implanted RF coils. Neuron. 2002; 35:227-242. [PubMed: 12160742]

Lowe AS, Beech JS, Williams SC. Small animal, whole brain fMRI: innocuous and nociceptive forepaw stimulation. Neuroimage. 2007; 35:719-728. [PubMed: 17300960]

Lu H, Patel S, Luo F, Li SJ, Hillard CJ, Ward BD, Hyde JS. Spatial correlations of laminar BOLD and $\mathrm{CBV}$ responses to rat whisker stimulation with neuronal activity localized by Fos expression. Magn. Reson. Med. 2004; 52:1060-1068. [PubMed: 15508149]

Lubke J, Feldmeyer D. Excitatory signal flow and connectivity in a cortical column: focus on barrel cortex. Brain Struct. Funct. 2007; 212:3-17. [PubMed: 17717695]

Lynn B, Carpenter SE. Primary afferent units from the hairy skin of the rat hind limb. Brain Res. 1982; 238:29-43. [PubMed: 6282398]

Mandeville JB, Marota JJ, Kosofsky BE, Keltner JR, Weissleder R, Rosen BR, Weisskoff RM. Dynamic functional imaging of relative cerebral blood volume during rat forepaw stimulation. Magn. Reson. Med. 1998; 39:615-624. [PubMed: 9543424]

Masamoto K, Kim T, Fukuda M, Wang P, Kim SG. Relationship between neural, vascular, and BOLD signals in isoflurane-anesthetized rat somatosensory cortex. Cereb. Cortex. 2007; 17:942-950. [PubMed: 16731882]

McAllister JP, Wells J. The structural organization of the ventral posterolateral nucleus in the rat. J. Comp. Neurol. 1981; 197:271-301. [PubMed: 7276236]

Meyer HS, Wimmer VC, Oberlaender M, de Kock CP, Sakmann B, Helmstaedter M. Number and laminar distribution of neurons in a thalamocortical projection column of rat vibrissal cortex. Cereb. Cortex. 2010; 20:2277-2286. [PubMed: 20534784]

Mitzdorf U. Current source-density method and application in cat cerebral cortex: investigation of evoked potentials and EEG phenomena. Physiol. Rev. 1985; 65:37-100. [PubMed: 3880898]

Mitzdorf U. Properties of the evoked potential generators: current source-density analysis of visually evoked potentials in the cat cortex. Int. J. Neurosci. 1987; 33:33-59. [PubMed: 3610492]

Muir ER, Duong TQ. MRI of retinal and choroidal blood flow with laminar resolution. NMR Biomed. 2011; 24:216-223. [PubMed: 20821409]

Nielsen AN, Lauritzen M. Coupling and uncoupling of activity-dependent increases of neuronal activity and blood flow in rat somatosensory cortex. J. Physiol. 2001; 533:773-785. [PubMed: 11410634]

Ogawa S, Lee TM, Stepnoski R, Chen W, Zhu XH, Ugurbil K. An approach to probe some neural systems interaction by functional MRI at neural time scale down to milliseconds. Proc. Natl. Acad. Sci. U. S. A. 2000; 97:11026-11031. [PubMed: 11005873]

Olman CA, Harel N, Feinberg DA, He S, Zhang P, Ugurbil K, Yacoub E. Layer-specific fMRI reflects different neuronal computations at different depths in human V1. PLoS One. 2012; 7:e32536. [PubMed: 22448223]

Patel U. Non-random distribution of blood vessels in the posterior region of the rat somatosensory cortex. Brain Res. 1983; 289:65-70. [PubMed: 6661656]

Pettersen KH, Devor A, Ulbert I, Dale AM, Einevoll GT. Current-source density estimation based on inversion of electrostatic forward solution: effects of finite extent of neuronal activity and conductivity discontinuities. J. Neurosci. Methods. 2006; 154:116-133. [PubMed: 16436298]

Polimeni JR, Fischl B, Greve DN, Wald LL. Laminar analysis of 7 T BOLD using an imposed spatial activation pattern in human V1. NeuroImage. 2010; 52:1334-1346. [PubMed: 20460157]

Sakata S, Harris KD. Laminar structure of spontaneous and sensory-evoked population activity in auditory cortex. Neuron. 2009; 64:404-418. [PubMed: 19914188]

Schouenborg J, Kalliomaki J, Gustavsson P, Rosen I. Field potentials evoked in rat primary somatosensory cortex (SI) by impulses in cutaneous A beta- and C-fibres. Brain Res. 1986; 397:86-92. [PubMed: 3801867]

Schubert D, Kotter R, Staiger JF. Mapping functional connectivity in barrel-related columns reveals layer- and cell type-specific microcircuits. Brain Struct. Funct. 2007; 212:107-119. [PubMed: 17717691]

Shen Q, Ren H, Duong TQ. CBF, BOLD, CBV, and CMRO(2) fMRI signal temporal dynamics at 500-msec resolution. J. Magn. Reson. Imaging. 2008; 27:599-606. [PubMed: 18219630] 
Sheth SA, Nemoto M, Guiou M, Walker M, Pouratian N, Toga AW. Linear and nonlinear relationships between neuronal activity, oxygen metabolism, and hemodynamic responses. Neuron. 2004; 42:347-355. [PubMed: 15091348]

Shih YY, Chen CC, Shyu BC, Lin ZJ, Chiang YC, Jaw FS, Chen YY, Chang C. A new scenario for negative functional magnetic resonance imaging signals: endogenous neurotransmission. $\mathrm{J}$. Neurosci. 2009; 29:3036-3044. [PubMed: 19279240]

Shih YY, Wey HY, De La, Garza BH, Duong TQ. Striatal and cortical BOLD, blood flow, blood volume, oxygen consumption, and glucose consumption changes in noxious forepaw electrical stimulation. J. Cereb. Blood Flow Metab. 2011; 31:832-841. [PubMed: 20940730]

Shih YY, Chiang YC, Shyu BC, Jaw FS, Duong TQ, Chang C. Endogenous opioid-dopamine neurotransmission underlie negative CBV fMRI signals. Exp. Neurol. 2012a; 234:382-388. [PubMed: 22245158]

Shih YY, Li G, Muir ER, De La, Garza BH, Kiel JW, Duong TQ. Pharmacological MRI of the choroid and retina: Blood flow and BOLD responses during nitroprusside infusion. Magn. Reson. Med. 2012b; 68:1273-1278. [PubMed: 22183830]

Shih YY, Muir ER, Li G, De La, Garza BH, Duong TQ. High-resolution 3D MR microangiography of the rat ocular circulation. Radiology. 2012c; 264:234-241. [PubMed: 22523323]

Siero JC, Petridou N, Hoogduin H, Luijten PR, Ramsey NF. Cortical depth-dependent temporal dynamics of the BOLD response in the human brain. J. Cereb. Blood Flow Metab. 2011; 31:19992008. [PubMed: 21505479]

Silva AC, Koretsky AP. Laminar specificity of functional MRI onset times during somatosensory stimulation in rat. Proc. Natl. Acad. Sci. U. S. A. 2002; 99:15182-15187. [PubMed: 12407177]

Silva AC, Lee SP, Iadecola C, Kim SG. Early temporal characteristics of cerebral blood flow and deoxyhemoglobin changes during somatosensory stimulation. J. Cereb. Blood Flow Metab. 2000; 20:201-206. [PubMed: 10616809]

Silva AC, Koretsky AP, Duyn JH. Functional MRI impulse response for BOLD and CBV contrast in rat somatosensory cortex. Magn. Reson. Med. 2007; 57:1110-1118. [PubMed: 17534912]

Smirnakis SM, Schmid MC, Weber B, Tolias AS, Augath M, Logothetis NK. Spatial specificity of BOLD versus cerebral blood volume fMRI for mapping cortical organization. J. Cereb. Blood Flow Metab. 2007; 27:1248-1261. [PubMed: 17213863]

Sun JJ, Yang JW, Shyu BC. Current source density analysis of laser heat-evoked intra-cortical field potentials in the primary somatosensory cortex of rats. Neuroscience. 2006; 140:1321-1336. [PubMed: 16675140]

Tenke CE, Schroeder CE, Arezzo JC, Vaughan HG Jr. Interpretation of high-resolution current source density profiles: a simulation of sublaminar contributions to the visual evoked potential. Exp. Brain Res. 1993; 94:183-192. [PubMed: 8359238]

Tian P, Teng IC, May LD, Kurz R, Lu K, Scadeng M, Hillman EM, De Crespigny AJ, D'Arceuil HE, Mandeville JB, Marota JJ, Rosen BR, Liu TT, Boas DA, Buxton RB, Dale AM, Devor A. Cortical depth-specific microvascular dilation underlies laminar differences in blood oxygenation leveldependent functional MRI signal. Proc. Natl. Acad. Sci. U. S. A. 2010; 107:15246-15251. [PubMed: 20696904]

Torebjork HE. Afferent $\mathrm{C}$ units responding to mechanical, thermal and chemical stimuli in human nonglabrous skin. Acta Physiol. Scand. 1974; 92:374-390. [PubMed: 4141858]

Van Hees J, Gybels JM. Pain related to single afferent C fibers from human skin. Brain Res. 1972; 48:397-400. [PubMed: 4645215]

Van CN, Verhoye M, Van der LA. Stimulation of the rat somatosensory cortex at different frequencies and pulse widths. NMR Biomed. 2006; 19:10-17. [PubMed: 16408324]

Viswanathan A, Freeman RD. Neurometabolic coupling in cerebral cortex reflects synaptic more than spiking activity. Nat. Neurosci. 2007; 10:1308-1312. [PubMed: 17828254]

White EL. Thalamocortical synaptic relations: a review with emphasis on the projections of specific thalamic nuclei to the primary sensory areas of the neocortex. Brain Res. 1979; 180:275-311. [PubMed: 394815]

Wojcik DK, Leski S. Current source density reconstruction from incomplete data. Neural Comput. 2010; 22:48-60. [PubMed: 19764876] 
Woolsey TA, Rovainen CM, Cox SB, Henegar MH, Liang GE, Liu D, Moskalenko YE, Sui J, Wei L. Neuronal units linked to microvascular modules in cerebral cortex: response elements for imaging the brain. Cereb. Cortex. 1996; 6:647-660. [PubMed: 8921201]

Yu X, Glen D, Wang S, Dodd S, Hirano Y, Saad Z, Reynolds R, Silva AC, Koretsky AP. Direct imaging of macrovascular and microvascular contributions to BOLD fMRI in layers IV-V of the rat whisker-barrel cortex. NeuroImage. 2012; 59:1451-1460. [PubMed: 21851857]

Zhao F, Wang P, Kim SG. Cortical depth-dependent gradient-echo and spin-echo BOLD fMRI at 9.4 T. Magn. Reson. Med. 2004; 51:518-524. [PubMed: 15004793]

Zhao F, Wang P, Hendrich K, Ugurbil K, Kim SG. Cortical layer-dependent BOLD and CBV responses measured by spin-echo and gradient-echo fMRI: insights into hemodynamic regulation. NeuroImage. 2006; 30:1149-1160. [PubMed: 16414284]

Zheng D, LaMantia AS, Purves D. Specialized vascularization of the primate visual cortex. J. Neurosci. 1991; 11:2622-2629. [PubMed: 1714496] 

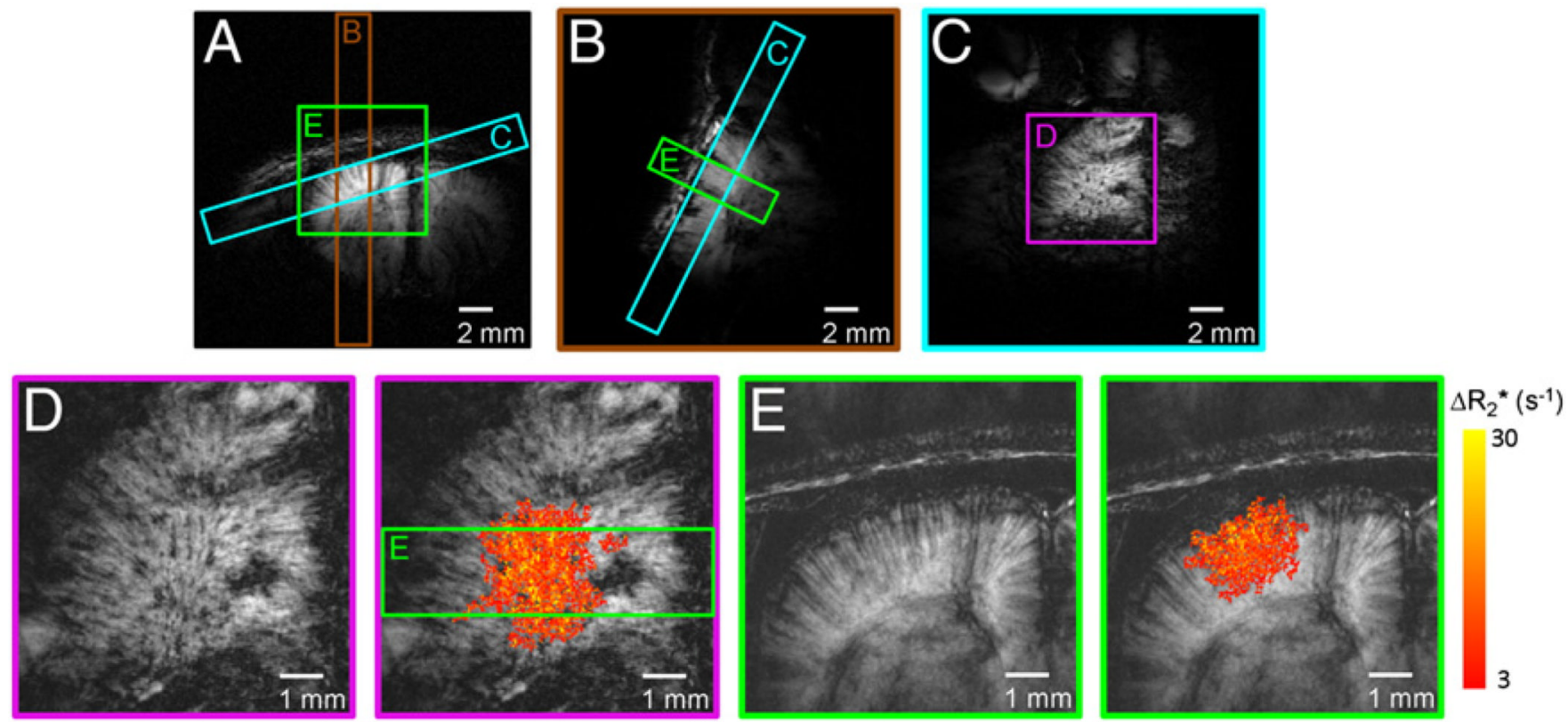

Fig. 1.

High resolution MRI and CBV-weighted fMRI. Data were acquired by using a customdesigned coil (ID 0.7 cm) at an $11.7 \mathrm{~T}$ MRI scanner. The coil was placed above the left S1FL to provide better signal-to-noise ratio. Post-MION (A) axial and (B) sagittal images with $20 \mathrm{~mm}$ FOV. (C) Horizontal image was acquired parallel to the surface of the left S1FL as shown in A \& B. (D) Horizontal image with the same position as $\mathrm{C}$ but with smaller FOV $(7.68 \mathrm{~mm})$. Forepaw stimulation at $2 \mathrm{~mA}, 0.3 \mathrm{~ms}$ pulse width, and $3 \mathrm{~Hz}$ was applied to identify the activation area. (E) Axial image perpendicular to the cortical surface and parallel to the cortical penetrating vessels with $7.68 \mathrm{~mm}$ FOV as shown in A, B, and D. This slice position was used for the rest of the fMRI studies. 

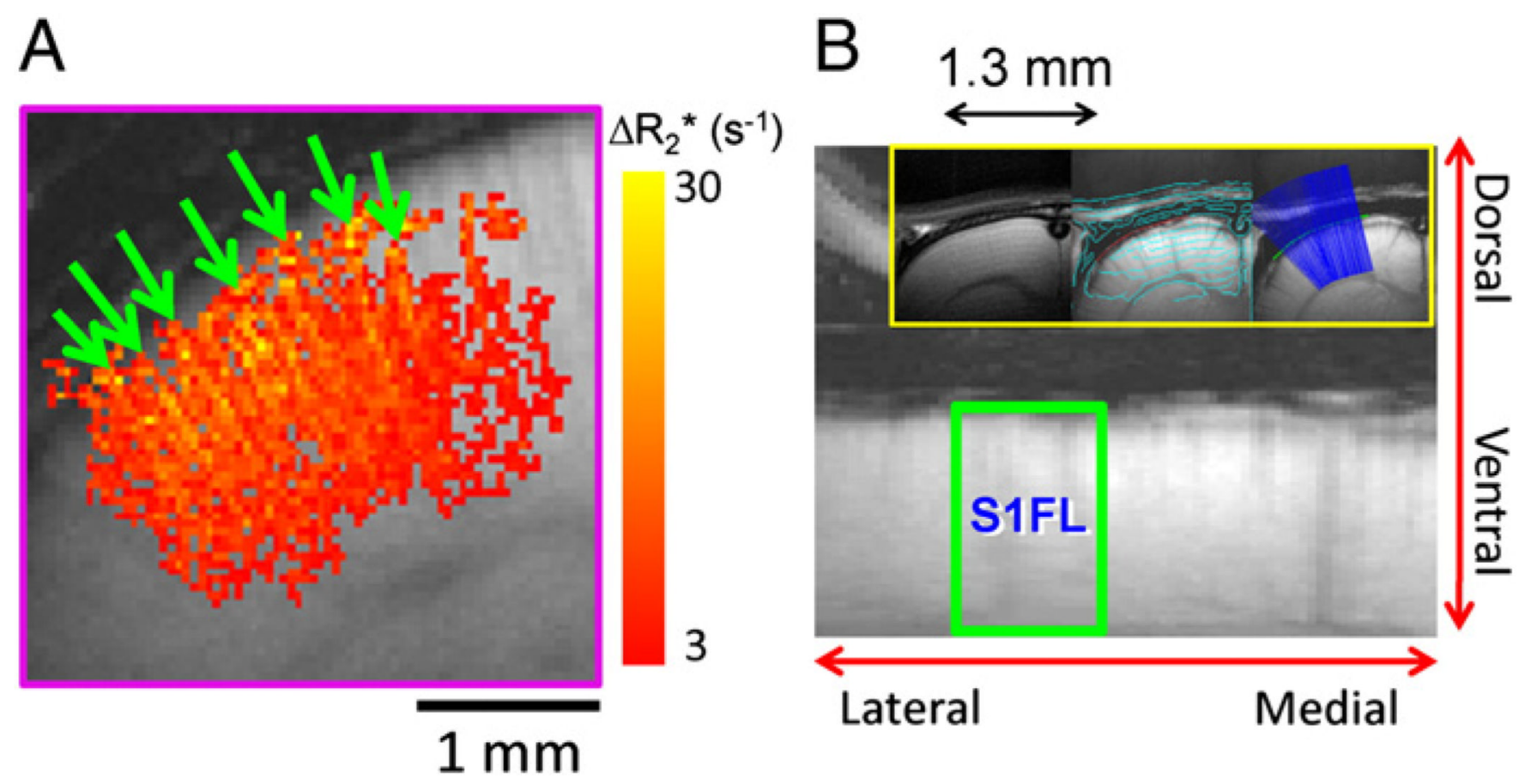

Fig. 2.

High resolution CBV-weighted fMRI responses. (A) Column-like activation was observed in the contralateral S1FL which may originate from penetrating vessels. Stimulation paradigm was $2 \mathrm{~mA}, 0.3 \mathrm{~ms}$ pulse width, and $3 \mathrm{~Hz}$. (B) Linearized cortical image. To achieve laminar analysis, the cortex was linearized via finding the edge of the cortical surface and radially projecting lines perpendicular to the edge (inset). Cortical surface and corpus callosum can be more clearly identified on the pre-MION FLASH image. The depth of the S1FL is generally $2 \mathrm{~mm}$. 
A
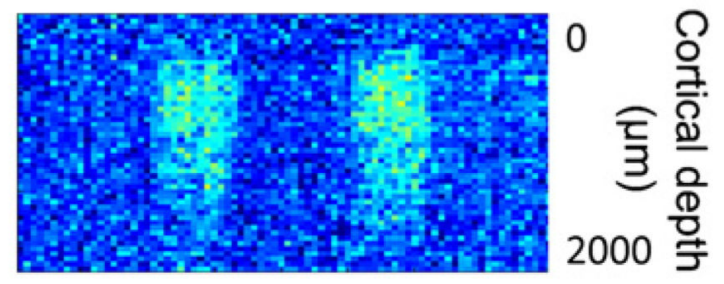

$2 \mathrm{~mA}$

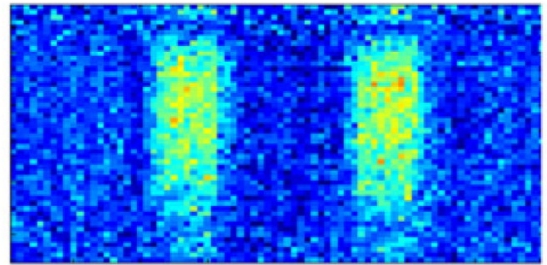

$6 \mathrm{~mA}$

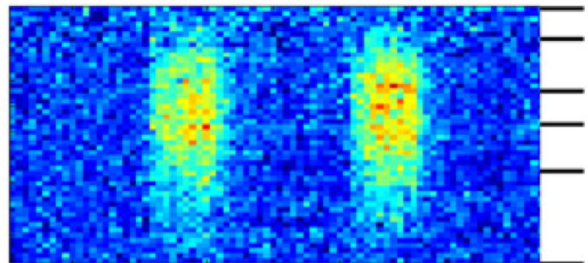

$10 \mathrm{~mA}$

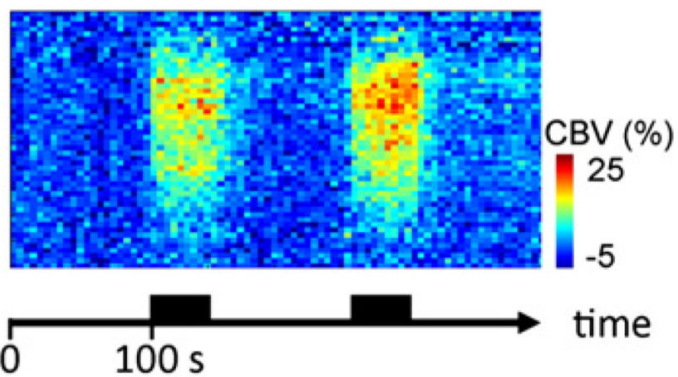

B
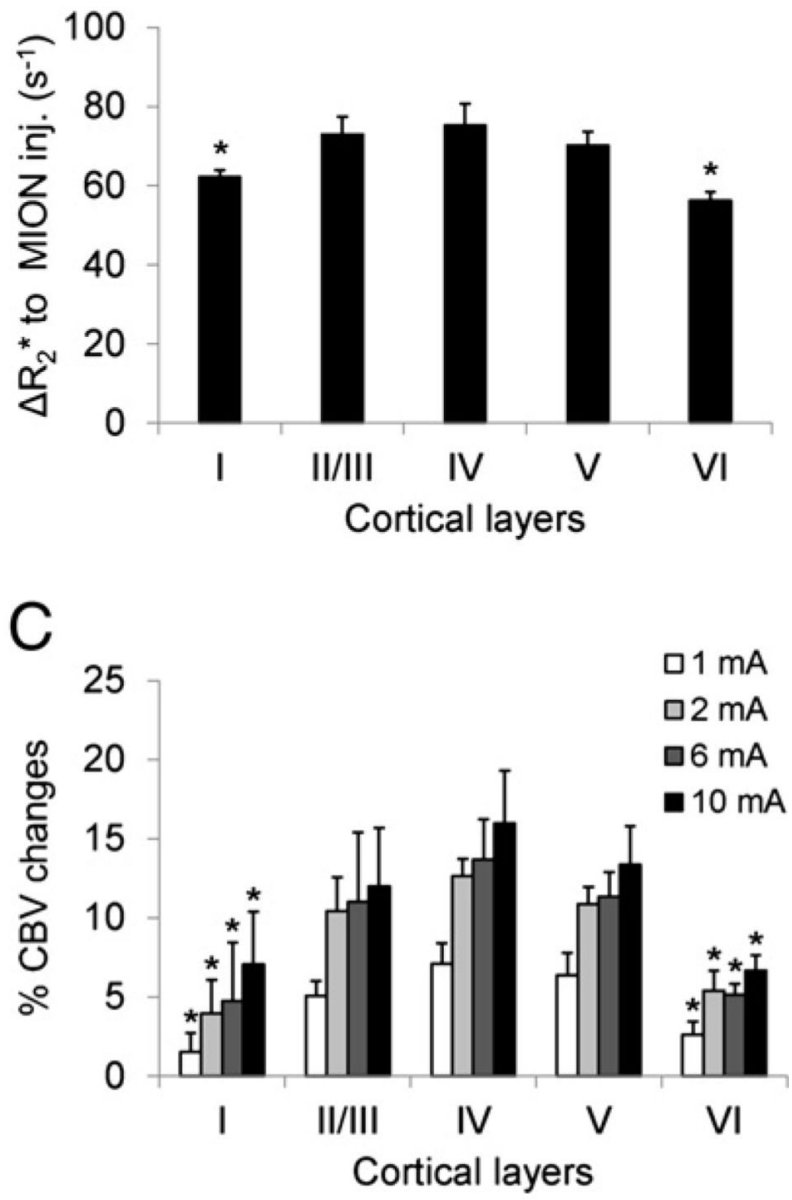

Fig. 3.

Group averaged CBV responses to graded forepaw electrical stimulation. (A) Averaged CBV fMRI time course of different stimulus amplitudes $(\mathrm{n}=6)$. The ROI was $1.3 \times 2 \mathrm{~mm}^{2}$ (shown in Fig. 2B) and centered to the activation site. Data were averaged across the lateral to the medial side and plotted over time. The $\mathrm{X}$-axis indicates imaging time period, while the $\mathrm{Y}$-axis represents cortical depth. The black boxes indicate stimulation epochs. (B) Basal CBV fraction $\left(\Delta \mathrm{R}_{2} *\right)$ at different cortical layers. (C) Percent CBV changes to graded forepaw electrical stimulation at different cortical layers $(n=6)$. *Significantly different from layer IV; Significant level was set at $P<0.05$. Error bars are s.e.m. values. 

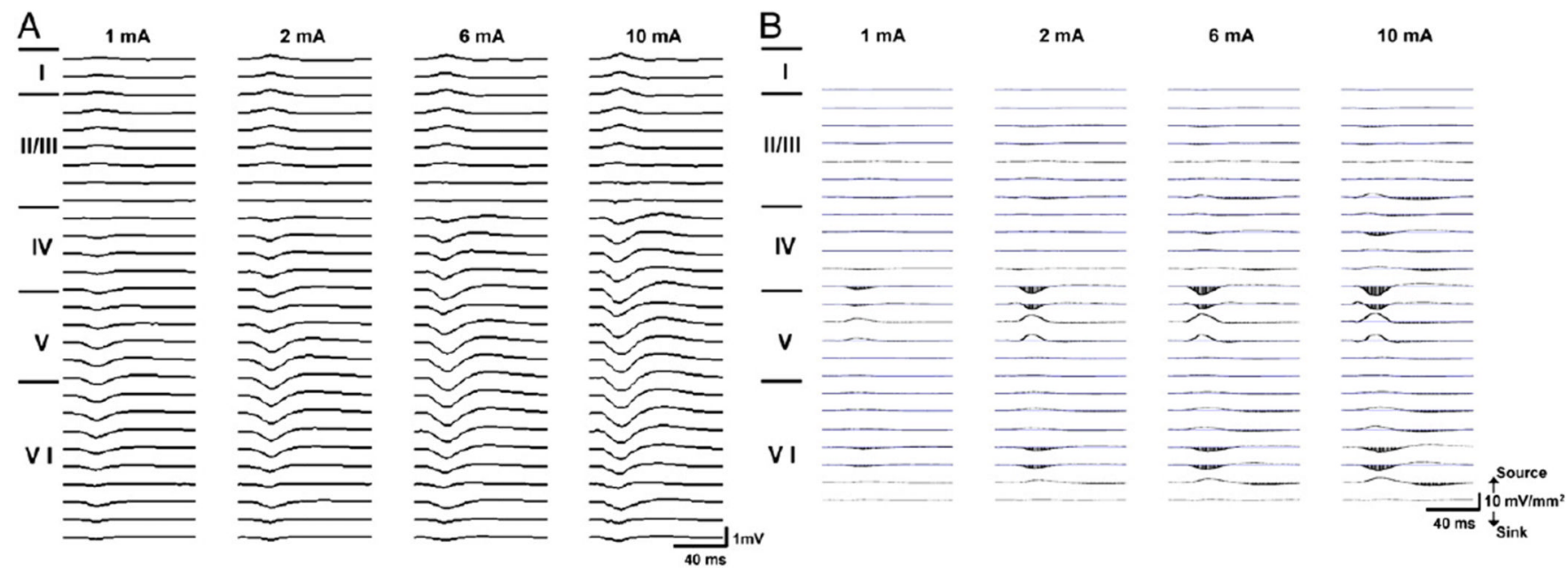

Fig. 4.

(A) Representative LFP averaged from 150 trials during graded forepaw electrical stimulation. (B) Corresponding CSD laminar responses to graded forepaw electrical stimulation. The sink and source current traces were derived from averaged LFP. Zero current base lines were drawn to divide the sink and source currents. The sink current was downward directed and marked with shade. The CSD traces showed apparent sink currents at layers IV and VI. 

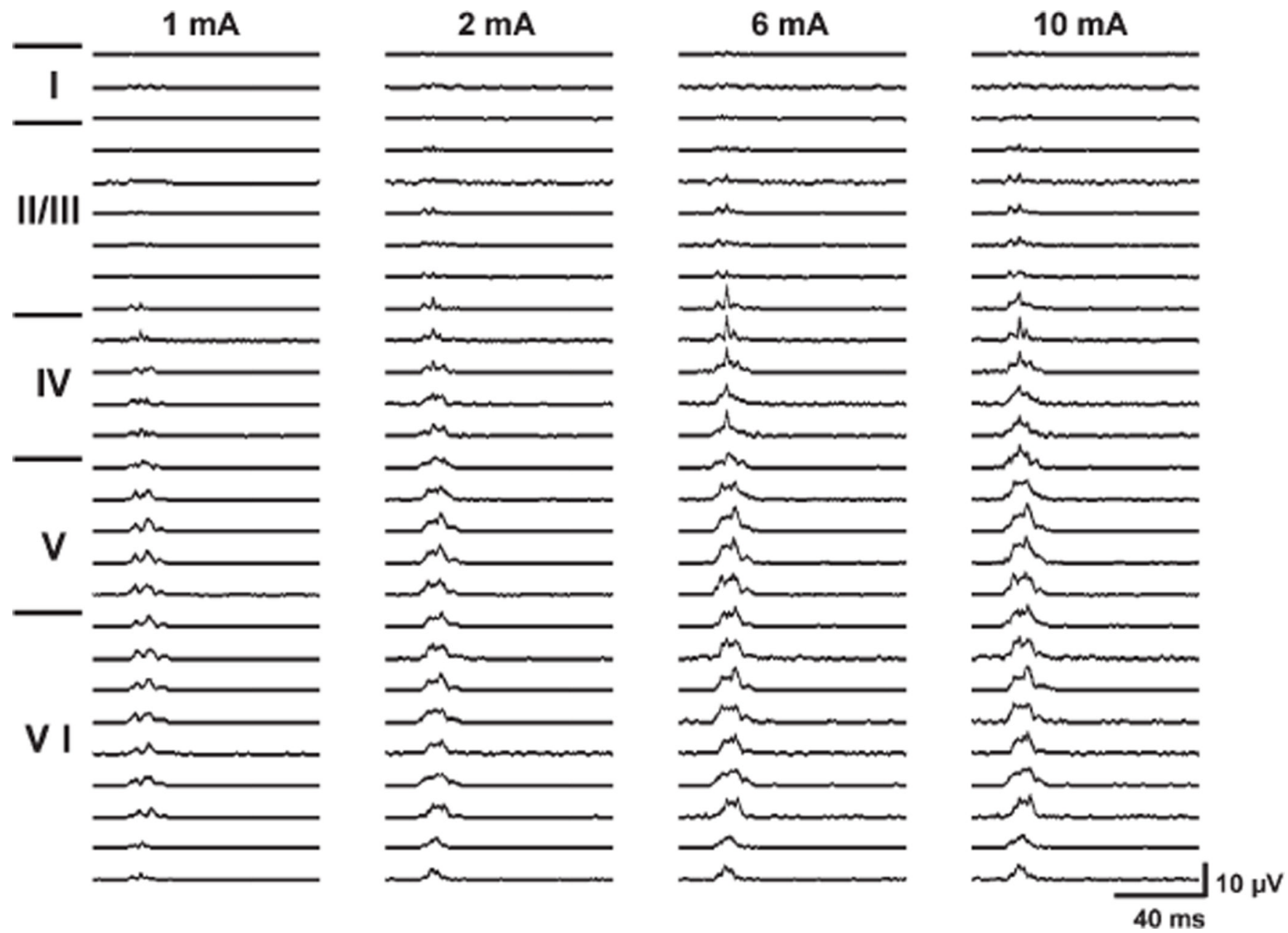

Fig. 5.

Representative MUA traces during graded forepaw electrical stimulation. The responses mainly located at layers IV-VI. 

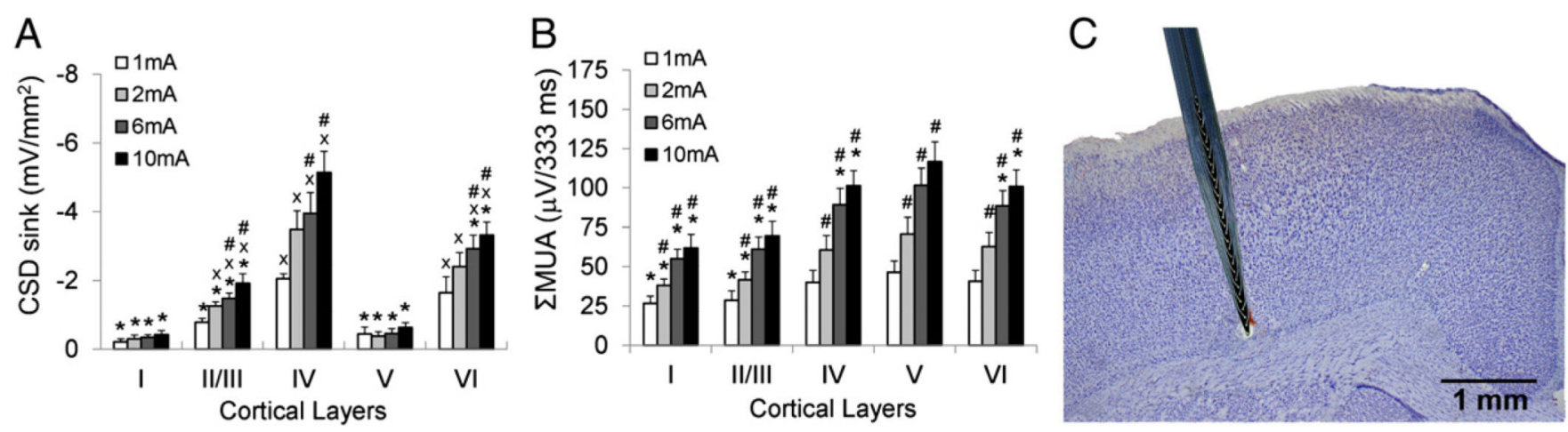

Fig. 6.

Group averaged CSD and MUA responses to graded forepaw electrical stimulation. (A) Group-averaged CSD $(n=5)$ of different stimulus amplitudes. The first CSD sink amplitude (inward current) was quantified at different cortical layers. *Significantly different from layer IV. ${ }^{x}$ Significantly different from layer I. ${ }^{\#}$ Significantly different from $1 \mathrm{~mA}$. (B) Group-averaged MUA ( $n=5)$ of different stimulus amplitudes. $\sum$ MUAs were calculated by integrating the area under the response curve during the first $100 \mathrm{~ms}$ after the stimulus onset. *Significantly different from layer V; \#Significantly different from $1 \mathrm{~mA}$; Significant level was set at $P<0.05$. Error bars are s.e.m. values. (C) Reference lesion site (arrowhead) was observed at the boundary of the cortical layer VI and corpus callosum. Lesion was induced by passing an anodal current $(30 \mu \mathrm{A}$ for $10 \mathrm{~s})$ to the $32 \mathrm{nd}$ contact lead at the end of the experiment to confirm the recording site and ensure that the 32 recording channels spanned the entire cortical depth. 